\title{
PTERIDÓFILAS PECOPTERÓIDES DA FORMAÇĀO RIO DO RASTO NO ESTADO DO PARANÁ E DA FORMAÇĀO ESTRADA NOVA NO ESTADO DE SĀO PAULO (BACIA DO PARANÁ, PERMIANO SUPERIOR) $)^{1,2}$
}

\author{
Rosemarie Rohn ${ }^{3}$
}

Oscar Rösler"

\begin{abstract}
This paper deals with Pteridophylla and Filicophyta from 23 outcrops of the Rio do Rasto Formation in Paraná State and 2 outcrops of the Estrada Nova Formation in São Paulo State (Passa Dois Group, Paraná Basin, Upper Permian). Equivalent fossils have been described previously from only 3 localities of these same stratigraphic units. The fossils occur as impressions of fragmented fronds and pinnae in red, gray and yellowish mudstones, siltstones and fine sandstones. All the better preserved pecopterids correspond to new species: Pecopteris taguaiensis, $P$. dolianitii, $P$. esperancensis, $P$. bracatingaensis and $P$. cadeadensis. Other described specimens are considered as Pecopteris sp.1, P. sp.2, P. sp.3, ?Dizeugotheca bortoluzzii Cazzulo-Klepzig and ?Dizeugotheca sp.
\end{abstract}

\section{INTRODUÇĀO}

As pteridófilas pecopteróides, que incluem as filicófitas e as pterospermáfitas semelhantes ao morfogenero Pecopteris, såo relativamente comuns na Formação Rio do Rasto (Grupo Passa Dois, Permiano Superior). Entretanto, ainda não mereceram muitos estudos visando a sua classificação ou aplicação bioestratigráfica. Para esta unidade, as pteridófilas pecopteróides foram anteriormente citadas ou descritas por OLIVEIRA (in HOLDHAUS, 1918), DOLIANITI (1945), MENDES (1954), RÖS. LER (1978), CAZZULO-KLEPZIG (1978) e CAZZULO-KLEPZIG \& CORREIA (1981). Em relaçāo à Formação Estrada Nova ou Corumbataí (Grupo Passa Dois, Permiano Superior), há somente uma sumária descriçăo das pteridófilas pecopteróides da regiāo de Laras, SP (RIGBY, 1968).

MAITHY (1977), entre outros autores, observou que as pteridófilas estéreis do Gondwana sฮ̃o apenas superficialmente semelhantes a morfogéneros carboníferos do Hemisfério Norte como Sphenopteris, Pecopteris, Alethopteris e Merianopteris. Na India, as formas es- téreis estão recebendo novas designaçốes genéricas e específicas, e sua classificação está baseada, respectivamente, no padrão de nervaçăo $\mathrm{e}$ na morfologia das pinulas (MAITHY, 1977). Embora admitindo os problemas implícitos em adotar os nomes de taxa de outras províncias paleofloristicas, no presente trabalho, decidiuse pela utilizaçáo do consagrado termo Pecopteris devido às dificuldades no reconhecimento das verdadeiras relaçóes filogenéticas entre as espécies. A classificação proposta é meramente artificial, porém adequada aos propósitos da pesquisa em andamento sobre a bioestratigrafia e paleoambiente da Formação Rio do Rasto, onde os resultados deste trabalho serão aplicados. Portanto, com base em 78 exemplares (de um total de 145), coletados em 23 afloramentos da Formação Rio do Rasto no Estado do Paraná e em 2 afloramentos da Formação Es. trada Nova no Estado de São Paulo, são descritas as seguintes espécies: Pecopteris taguaiensis n. sp., $P$. dolianitii n. sp., $P$. esperancensis n. sp., $P$. bracatinguensis n. $\mathrm{sp} ., P$. cadeadensis $\mathrm{n}$. sp., Pecopteris sp. 1, P. sp.2, P. sp.3, ?Dizeugotheca bortoluzzii Cazzulo-Klepzig, 1978 e ?Dizeugotheca sp.

1 Contribuição ao Projeto n! 237 ("Gondwana Floras") do Programa Internacional de Correlação Geológica, IUGSUNESCO.

2 Trabalho realizado com o apoio financeiro da FAPESP (Proc. № 83/2220-0).

3 Pós-graduanda do IG-USP e Bolsista da FAPESP (Proc. No 82/2096-5).

4 IG-USP. 


\section{MATERIAL E PROCEDENCIA}

Os fósseis estáo preservados como impressões e contra-impressōes, sem remanescência de cutícula ou de quaisquer outras substâncias organicas. Ocorrem em argilitos e siltitos, em geral, praticamente maciços, compactos, com fratura conchoidal ou com incipiente laminação plano-paralela, ou ainda, em arenitos finos, ligeiramente rítmicos, com laminaçāo gradacional, mais ou menos compactos. Frequuentemente, a nervação das pínulas está ressaltada por contraste cromático.

Os afloramentos listados abaixo foram numerados conforme a sigla $\mathrm{AF} / \mathrm{GP}$ utilizada no Departamento de Paleontologia e Estratigrafia do Instituto de Geociências da Universidade de São Paulo. As amostras estudadas estão depositadas na coleção paleobotânica do mesmo departamento, sob a sigla GP/3T.

\section{Lista das localidades}

- AF/GP 5 - estrada Taquarituba-Fartura, a cerca de $3 \mathrm{~km}$ a sudeste de Taguaí, Pedreira Velha, Fazenda São Vicente, SP; siltito cinza com carbonato de cálcí; Pecopteris taguatensis, $P$. dolianitii.

- AF/GP 7 - estrada Laranjal Paulista-Laras, a $4 \mathrm{~km}$ de Laras, SP; argilito cor-de-vinho; Pecopteris taguaiensis.

- AF/GP 157 - estrada Mallet-Dorizon, a cerca de $5,1 \mathrm{~km}$ a sul de Mallet, PR; siltito corde-vinho; Pecopteris dolianitii, Pecopteris cf. P. esperancensis, Pecopteris sp.2., ?Dizeugotheca bortoluzzii, ?Dizeugotheca sp.

- AF/GP 168 - estrada Rondinha-Paulo Frontin, a cerca de $400 \mathrm{~m}$ da BR 476, PR; nível 2; argilito cor-de-vinho; Pecopteris dolianitii, $P$. esperancensis, Pecopteris sp. 3 .

- AF/GP 172 - trevo BR 373-BR 277, PR; 2 niveis; siltito cinza e cor-de-vinho; Pecopteris cf. $P$. dolianitii, Pecopteris cf. P. esperancensis.

- AF/GP 178 - BR 476, aproximadamente km 206,5, PR; argilito cor-de-vinho; Pecopteris cf. P. dolianitii, Pecopteris sp. 1, Pecopteris sp. 2 .

- AF/GP 179 - BR 476, aproximadamente km 207,2, PR; argilito cor-de-vinho; Pecopteris sp. (provável $P$. dolianitii).

- AF/GP 185 - estrada Paulo Frontin-Rondi- nha, a cerca de $16,8 \mathrm{~km}$ de P. Frontin, PR; argilito siltoso vermelho-esverdeado variegado; Pecopteris cf. P. dolianitii.

- AF/GP 186 - estrada Paulo Frontin-Rondi. nha, a cerca de $12,4 \mathrm{~km}$ de P. Frontin, PR: argilito cinza-róseo-amarelado; Pecopteris dolianitii, Pecopteris cf. P. dolianitii.

- AF/GP 187 - estrada Paulo Frontin-Rondinha, a cerca de $7,3 \mathrm{~km}$ de P. Frontin, PR; siltito argiloso cor-de-vinho; Pecopteris cf. $\boldsymbol{P}$. bracatingaensis.

- AF/GP 194 - BR 277, aproximadamente km 303,5, PR; argilito cinza-róseo-amarelado; Pecopteris dolianitii, Pecopteris ef. $\boldsymbol{P}$. bracatingaensis, Pecopteris sp.1.

- AF/GP 197 - BR 373, aproximadamente km 103,8, PR; $P$. bracatingaensis, $P$. dolianitii, $P$. esperancensis, Pecopteris sp. 1, Pecopteris sp. 3,?Dizeugotheca sp.

- AF/GP 200 - estrada Reserva-Cândido de Abreu, a cerca de $31,5 \mathrm{~km}$ de Reserva, PR; Pecopteris cf. $P$. cadeadensis, Pecopteris dolianitii.

- AF/GP 201 - estrada Reserva-Cândido de Abreu, a cerca de $33,7 \mathrm{~km}$ de Reserva, PR; Pecopteris sp.

- AF/GP 210 - BR 376 (Rod. do Café), km 264,6, PR; siltito cinza; Pecopteris dolianitii, Pecopteris cf. P. bracatinguensis.

- AF/GP 211 - BR 376, km 266,1, PR; siltito argiloso cor-de-vinho; $P$. dolianitii.

- AF/GP 224 - BR 376, km 296,6, PR; siltito argiloso cinza-esverdeado; Pecopteris sp.

- AF/GP 227 - PR 90, aproximadamente km 118,8 , PR; siltito roxo; P. esperancensis.

- AF/GP 249 - BR 153, km 41,7, PR; siltito cor-de-vinho; ?Dizeugotheca sp.

- AF/GP 274 - estrada Rio Azul-Mallet, a cerca de $13,9 \mathrm{~km}$ de Rio Azul, PR; siltito arenoso cinza; $P$. dolianitii.

- AF/GP 275 - estrada Rio Azul-Mallet, a cerca de $1,3 \mathrm{~km}$ de Mallet, PR; siltito argiloso cor-de-vinho; Pecopteris sp. 1 .

- AF/GP 277 - estrada Rio Azul-Mallet, a cerca de $0,7 \mathrm{~km}$ de Mallet, PR; siltito argiloso cor-de-vinho; Pecopteris sp.

- AF/GP 284 - estrada lateral na altura do $\mathrm{km}$ 284,6 da BR 376 , a cerca de $3 \mathrm{~km}$ a leste do entroncamento, PR; siltito amarelado; $P$. cadeadensis.

- AF/GP 291 - estrada Mallet-Paulo Frontin, entre 3,3 e 3,6km de Mallet, PR; siltito arenoso levemente carbonático, cor-de-vinho; Pecopteris sp. (pínulas isoladas).

- AF/GP 301 - estrada Reserva-Cândido de Abreu, a cerca de $37,4 \mathrm{~km}$ de Reserva, PR; siltito argiloso cor-de-vinho; Pecopteris sp. (pínulas isoladas). 


\section{SISTEMÁTICA}

Um dos principais propósitos da paleobotânica é a escolha dos criterios adequados de classificação dos fitofósseis, por estes geralmente representarem somente fraçōes de um vegetal. WAĢNER (1968) elaborou uma chave de classificação de Alethopteris, cuja escala de critérios considerados, aparentemente, é a que se ajusta mais satisfatoriamente aos exemplares do gênero Pecopteris aqui analisados, embora com a introduçăo de algumas modificaçōes. Na medida do possivel, os principais critérios adotados, em ordem decrescente de importância, såo os seguintes: forma da pina; distanciamento entre as pínulas (levando em consideração coalescência lateral, imbricamento, etc.); forma e proporções médias das pínulas; decorrência ou não das nervuras medianas das pínulas; decorrência ou não e padrāo geral de encurvamento das nervuras secundárias; padrāo de distribuiçăo, densidade relativa e número de nervuras secundárias; e finalmente, caráter e pontos de localização das dicotomias nas nervuras secundárias. Os dados morfométricos são fornecidos na Tabela 1 e explicados na Fig. 1; referem-se apenas às espécies perfeitamente determinadas (não "cf."). Os valores quantitativos nas diagnoses das novas espécies têm uma representatividade de pelo menos $70 \%$.

\section{Grupo PTERIDOPHYLLA \\ Morfogênero Pecopteris (Brongniart, 1822) Sternberg, 1825}

Pecopteris taguaiensis $\mathrm{n} . \mathrm{sp}$. Figs. 2, 12 a 15; Tabela 1

Holótipo - GP/3T 1713bA; localidade. tipo: AF/GP 5 - Estrada Taquarituba-Fartura, a cerca de $3 \mathrm{~km}$ a sudeste de Taguaí, Pedreira Velha, Fazenda São Vicente, SP.

Paratipos - AF/GP 5 - GP/3T 1709 , $1710 \mathrm{~A}, \mathrm{~B}, 1711 \mathrm{~A}, 1712 \mathrm{a} / \mathrm{bA}, 1713 \mathrm{aD}, \mathrm{aE}, \mathrm{bB}$; outro exemplar: AF/GP 7 - GP/3T 1708A.

Epiteto especifico - taguaiensis referese à cidade de Taguaí, próxima à localidadetipo.

Diagnose - Frondes pelo menos bipinadas, com ráquis robusto, apresentando cicatrizes circulares de inserção de pelos relativamente grandes. Pinas oblongas, com relaçāo comprimento por largura próxima a 7,7 , inseridas segundo ângulos entre $43^{\circ}$ e $54^{\circ}$ no ráquis principal, em posiçåo alterna, próximas entre si ou até imbricadas. Ápice das pinas pouco agudo a obtuso, imparipinado e pinatifido. Ráquis das pinas estriado e provavelmente com carena longitudinal. Pínulas contiguas, inseridas com toda a sua base a quase $90^{\circ}$ ao ráquis, em posição frequientemente oposta, porém também alterna. Forma das pinulas oblonga, com margens laterais inteiras, lisas, aparentemente livres até a base, apresentando relaçāo comprimento por largura normalmente entre 2,4 e 2,9 . Ápice das pínulas arredondado, ocasionalmente um pouco encurvado para o lado distal. Nervaçăo das pinulas constituida por nervura mediana decorrente da carena do ráquis, com terminaçăo em dicotomia, e por mais ou menos 8 a 12 nervuras secundárias em cada lado da nervura mediana, geralmente emitidas segundo ângulos entre $50^{\circ}$ e $65^{\circ}$, dispostas em densidade não muito alta, opostas (ou subopostas, tendendo levemente ao padrão de distribuição catadrômico); curso das nervuras secundárias quase nāo decorrente, mais ou menos retilíneo e com uma dicotomia a um terço da distância entre as nervuras medianas e as margens; nervuras resultantes da dicotomia não muito divergentes, retilíneas e paralelas a levemente curvas e côncavas entre si; às vezes, presença de uma segunda dicotomia próxima às margens, desenvolvida no ramo acroscópico do primeiro par dicotômico. Calibre das nervuras das pinulas relativamente fino.

Observaçōes adicionais - As impressōes das pinulas apresentam-se bastante convexas nos exemplares de Taguaí e quase planas no exemplar de Laras. $\mathrm{O}$ caráter decorrente das nervuras medianas foi observado apenas próximo às carenas longitudinais, já no interior dos ráquis das pinas (aparecendo como sulco nas impressōes), dando razão a interpretar estas carenas como vasos vasculares principais dos ráquis. As nervuras medianas são retas, com leve encurvamento no ápice das pínulas ou apresentam suave zigue-zague conforme a emergência das nervuras secundárias. No exemplar GP/3T $1713 \mathrm{bA}$, ocorrem marcas arredondadas nas áreas interneurais, provavelmente correspondentes a impressōes de células. As dimensōes săo fornecidas na Tabela 1.

Discussão - A forma geral e a disposição das frondes, pinas e pinulas de $P$. taguaiensis lembram Dizengotheca waltonii Archangelsky \& de la Sota, 1960; contudo, as pínulas "estéreis" desta espécie ostentam nervuras secundárias não dicotomizadas.

$P$. taguaiensis apresenta pinas, pinulas e ráquis semelhantes a Pecopteris (Asterotheca?) frenguelli Archangelsky \& de la Sota, 1960 

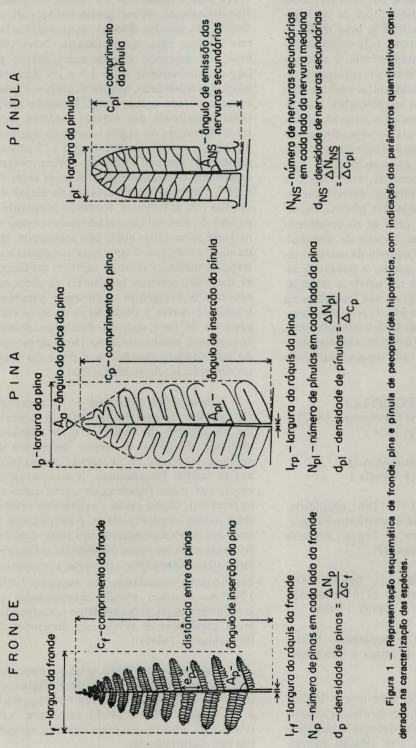
Paleobot. e Palinol. na América do Sul - 1985 - Bol. IG.USP, Inst. Geociénc., Univ. S. Paulo, 17: 1-147, 1986

\begin{tabular}{|c|c|c|c|c|c|c|c|c|c|c|c|c|c|c|c|c|c|c|c|c|}
\hline 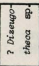 & 1 & 1 & 1 & 1 & 11 & 1 & $\cong$ & $\mid \begin{array}{l}\hat{N} \\
\hat{\wedge}\end{array}$ & 1 & & $b_{0}$ & 1 & $\stackrel{\infty}{*}$ & 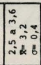 & $\begin{array}{l}n= \\
n \infty \\
n=0\end{array}$ & $\begin{array}{l}\tilde{2} \\
\tilde{n} \\
0 \\
a \\
i\end{array}$ & 1 & 1 & 1 & n \\
\hline 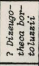 & 1 & 1 & 1 & 1 & 1 & 11 & $\approx$ & $\begin{array}{l}8 \\
\hat{\imath} \\
\end{array}$ & $\begin{array}{l}0 \\
\text { ì } \\
\text { ?an }\end{array}$ & & $\sum_{0}$ & 1 & $\overrightarrow{i v}$ & $\begin{array}{l}0 \\
0 \\
0 \\
0 \\
n \\
n\end{array}$ & "ू. & $\begin{array}{l}m \\
m \\
0 \\
a \\
n \\
i\end{array}$ & 1 & 1 & 1 & - \\
\hline $\begin{array}{ll}\frac{5}{5} & 7 \\
\frac{5}{8} & 0 \\
8 & 0 \\
2\end{array}$ & 1 & 1 & 1 & 1 & & & $\begin{array}{l}a \\
\text { ले } \\
\pi \\
a \\
\text { ते }\end{array}$ & $\begin{array}{l}\hat{a} \\
\hat{\imath}\end{array}$ & $\overrightarrow{0}$ & & : & 1 & $\stackrel{0}{\vdots}$ & 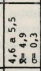 & 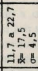 & 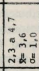 & 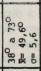 & i⿱ & \begin{tabular}{|c|}
0 \\
0 \\
0 \\
0 \\
0 \\
0 \\
$\vdots$ \\
0 \\
0 \\
\end{tabular} & $\infty$ \\
\hline 通 & 1 & 1 & 1 & 1 & & 1 & 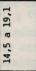 & $\begin{array}{l}\mathbf{D} \\
\mathbf{0} \\
\wedge\end{array}$ & 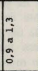 & & 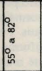 & 1 & $\begin{array}{l}2 \\
i \\
i \\
i\end{array}$ & 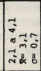 & 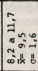 & 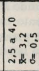 & 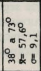 & 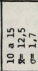 & 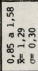 & $\mathrm{m}$ \\
\hline 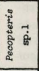 & 1 & 1 & I & 1 & & 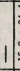 & 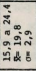 & ? & a & & 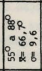 & 11 & 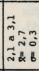 & 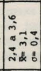 & 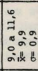 & 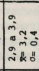 & 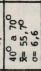 & $\begin{array}{l}\text { đun } \\
0 \neq 0 \\
0 \& 6\end{array}$ & 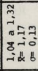 & in \\
\hline 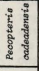 & 윰 & $\begin{array}{l} \\
\hat{n} \\
\hat{\imath}\end{array}$ & & & & $\begin{array}{l}2 \\
\vdots \\
0 \\
0 \\
2\end{array}$ & $\begin{array}{l}\pi \\
\vdots \\
\ddots\end{array}$ & $\stackrel{\infty}{\dddot{n}}$ & \begin{tabular}{l}
$n$ \\
\multirow{n}{n}{} \\
$n$ \\
$n$ \\
$-i$
\end{tabular} & & $\begin{array}{l}p_{n} \\
p^{n}\end{array}$ & $\begin{array}{l}m \\
n\end{array}$ & $\begin{array}{l}5 \\
\vdots \\
3\end{array}$ & $\begin{array}{l}7 \\
\infty \\
\infty \\
\infty\end{array}$ & $\begin{array}{l}0 \\
\vdots \\
\vdots \\
\vdots\end{array}$ & $\begin{array}{l}n \\
\text { sn } \\
\text { s. }\end{array}$ & $\begin{array}{l}\text { in } \\
\text { in } \\
\text { in } \\
\text { in }\end{array}$ & $\cong$ & 方热 & - \\
\hline 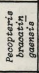 & $\begin{array}{l}\stackrel{\omega}{\omega} \\
\hat{\imath}\end{array}$ & ڤ̊ & ^ & 일 & $\begin{array}{l}8 \\
8 \\
8 \\
0 \\
7\end{array}$ & $\begin{array}{c}0 \\
0 \\
0 \\
0 \\
2\end{array}$ & 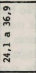 & ₹ & 总 & 1 & 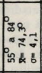 & $\cong$ & $\frac{\pi}{i}$ & 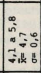 & 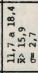 & 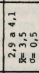 & 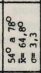 & 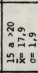 & 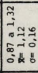 & 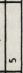 \\
\hline 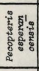 & 11 & 1 & 1 & 1 & & & 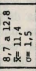 & $\hat{\imath}$ & 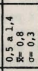 & ? & 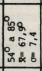 & 1 & 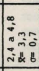 & 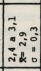 & $\begin{array}{l}2 \\
0 \\
0 \\
0\end{array}$ & 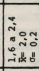 & 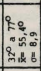 & 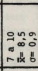 & 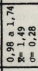 & . \\
\hline 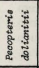 & 1 & 1 & 1 & 1 & & & 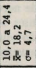 & {$\left[\begin{array}{l}8 \\
-1 \\
\wedge\end{array}\right.$} & 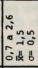 & 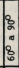 & 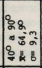 & $\begin{array}{l}n \\
n\end{array}$ & 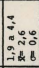 & 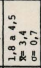 & 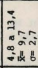 & 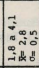 & 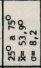 & 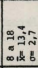 & 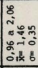 & $\approx$ \\
\hline 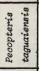 & : & $\hat{\imath}$ & $\begin{array}{l}-1 \\
\vdots \\
\vdots \\
5 \\
5\end{array}$ & 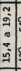 & $\begin{array}{l}0 \\
\vdots \\
0 \\
0 \\
0 \\
0\end{array}$ & \begin{tabular}{l|l}
0 \\
3 \\
0 \\
0 \\
0
\end{tabular} & 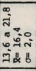 & 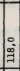 & 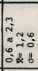 & $\begin{array}{l}8 \\
2 \\
2\end{array}$ & 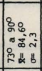 & $\frac{7}{5}$ & 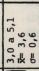 & 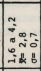 & 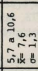 & 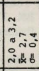 & 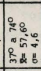 & 구워 & 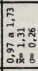 & 2 \\
\hline & $\begin{array}{l}\mathbf{E} \\
-4 \\
\end{array}$ & $\mid \begin{array}{l}\text { 震 } \\
\end{array}$ & I & & & & $\begin{array}{l}\text { E } \\
\text { 点 } \\
\end{array}$ & 畺 & $\begin{array}{l}\text { E } \\
\text { g } \\
\end{array}$ & 5 & है & & 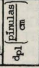 & $\begin{array}{l}\text { 自 } \\
\text { 年 }\end{array}$ & $\begin{array}{l}\bar{E} \\
\text { है } \\
\end{array}$ & $\vec{a}$ & $\begin{array}{l}\varepsilon \\
z\end{array}$ & $z$ & $\begin{array}{l}\text { E } \\
y \\
y \\
y\end{array}$ & $z$ \\
\hline
\end{tabular}

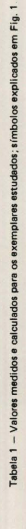




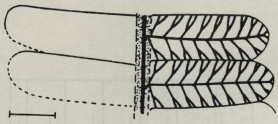

Figura 2 - Pecopteris tagualensis n. sp., holótipo. afloramento AF/GP 5, exemplar GP/3T 1713bA, escala - $3 \mathrm{~mm}$.

quanto à forma e à distribuição, e também nervuras finas, com uma dicotomia nas nervuras secundárias. Distingue-se pelo número maior e densidade mais alta de nervuras secundárias, pela sua emergência segundo ângulos mais abertos, pelo seu encurvamento menos acentuado, pelo padrão catadrômico pouco desenvolvido e pela falta de coalescência lateral na base das pínulas.

RIGBY (1968) descreveu um exemplar determinado como P. paranaensis Read, 1941, procedente de Laras, praticamente idéntico ao exemplar aqui analisado, coletado na mesma localidade. Ambos não têm as margens das pínulas bem preservadas, implicando na ilusão de que estăo mais afastadas entre si, com exceção da sua regiāo basal. $P$. taguaiensis, de fato, apresenta pinas semelhantes a $P$. paranaensis, conforme a sua diagnose original. Entretanto, as ilustraçōes desta espécie em READ (1941, Est. 2 , figs. 3 e 5 ) nāo permitem comparaçōes mais efetivas, percebendo-se apenas que suas nervuras secundárias são claramente alternas na base das pinulas, suas dicotomias ocorrem próximas às nervuras medianas e seus respectivos ramos são relativamente divergentes, ao contrário dos exemplares aqui descritos.

Pecopteris dolianitii n. sp.

Figs. 3, 16 a 23; Tabela 1

Holótipo - GP/3T $1669 \mathrm{a} / \mathrm{b} / \mathrm{cA}$; localidade-tipo: AF/GP 197 - BR 373, aproximadamente km 103,8, entre Prudentópolis e Relógio, PR.

Paritipos - AF/GP 197 - GP/3T 1667aA, $1719 \mathrm{~A}, 1720 \mathrm{a} / \mathrm{bA}$; outros exemplares: AF/GP 157 - GP/3T 546aC; AF/GP $168-$ GP/3T 1715,$1716 ; \mathrm{AF} / \mathrm{GP} 186$ - GP/3T 1717; AF/ GP 194 - GP/3T 1718B; AF/GP 210 - GP/3T $1722 \mathrm{a} / \mathrm{cA}, 1724 \mathrm{aA}, \mathrm{bB} ; \mathrm{AF} / \mathrm{GP} 211$ - GP/3T $1721 \mathrm{a} / \mathrm{bA} ; \mathrm{AF} / \mathrm{GP} 274$ - GP/3T 1756; AF/GP 5 - GP/3T 1726; exemplares considerados co- mo Pecopteris cf. P. dolianitii: AF/GP 172 GP/3T 1661, 1727, 1728a; AF/GP 178 - GP/ 3T $1743 \mathrm{gG} ; \mathrm{AF} / \mathrm{GP} 185-\mathrm{GP} / 3 \mathrm{~T} 1730 ; \mathrm{AF} /$ GP 186 - GP/3T 1731C;AF/GP 200 - GP/3T 1732A; AF/GP 210 - GP/3T 1723A, 1725A, B, C.

Epiteto especifico - dolianitii, em memória ao saudoso paleobotânico brasileiro Elias Dolianiti

Diagnose - Pinas suavemente oblongolanceoladas, retilíneas, com ápice tendendo a pinatífido, mais ou menos acuminado, imparipinado. Ráquis das pinas apresentando, como principal característica, um sulco longitudinal. Pínulas comumente em posição alterna, bastante próximas umas das outras, coalescidas ou justapostas na porção basal, formando ângulos normalmente de $55^{\circ}$ a $75^{\circ}$ em relação ao ráquis. Forma das pínulas oblonga, levemente falciforme com margens inteiras, lisas, paralelas até mais ou menos próximo ao ápice, tendo relação comprimento por largura geralmente entre 2,4 e 3,6. Ápice das pinulas arredondado a agudo-arredondado; base totaimente atada ao ráquis. Nervação das pínulas representada por nervura mediana não decorrente, com terminação apical aparentemente em dicotomia, e por aproximadamente 10 a 15 nervuras secundárias de calibre grosso em cada lado da pínula, em grande densidade, com padrão de distribuição catadrömico na porção basal das pínulas, porém já ocorrendo opostas mais ou menos a partir da porção média. Nervuras secundárias ligeiramente decorrentes, emitidas segundo ângulos não muito agudos, via de regra, apresentando uma dicotomia à pequena distância da nervura mediana, às vezes, com uma segunda dicotomia próximo às margens, desenvolvida apenas nos ramos acroscópicos das primeiras; dicotomias formadas por pares de nervuras assimétricas, um pouco mais divergentes somente após o ponto de bifurcação, senฮ̄o quase paralelas, pouco afastadas entre si, suavemente encurvadas, atingindo as margens laterais quase ortogonalmente.

Observaçōes adicionais - As porções mais próximas das pinas tendem a apresentar margens quiase paralelas. $O$ ráquis, além do sulco longitudinal que ocupa aproximadamente $1 / 4$ da sua largura, apresenta ainda estriaçōes e possivelmente cicatrizes de inserçāo de pelos (GP/ 3T $1722 \mathrm{a} / \mathrm{cA}$ ). A coalescência basal entre as pínulas ou, pelo menos, sua justaposiçăo muitas vezes não é perceptivel por falta de preservação adequada. Em alguns exemplares (GP/3T $546 \mathrm{aC}$, Fig. 22; GP/3T $1721 \mathrm{a} / \mathrm{bA})$, as pinulas 

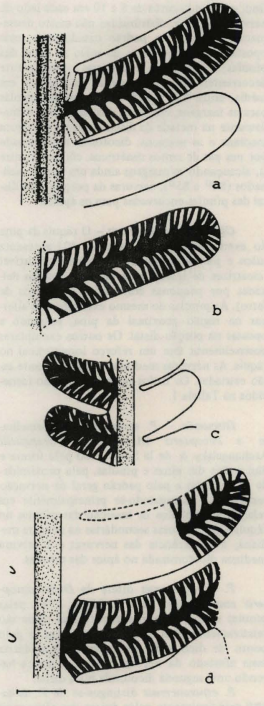

3

Figura 3 - Pacopteris dolianitil n. sp., escala = 3mm: (a) holótipo, afloramento AF/GP 197. exemplar GP/3T 1669aA; (b) afloramento AF/GP 168, exemplar GP/3T 1715; (c) afloramento AF/ GP 168, exemplar GP/3T 1716; (d) afioramento AF/GP 186, exemplar GP/3T 1717. ocorrem convexas, com as margens encurvadas para a face abaxial; nestes casos, o espaço relativamente largo deixado entre a impressāo da provável porção abaxial e a "moldura" corres. pondente ao perfil da impressão da porção abaxial sugere limbo mais ou menos espesso e/ou margens das pínulas enroladas sobre si mesmas. As nervuras medianas estreitam-se para o ápice; às vezes, exibem estrias longitudinais; frequientemente, apresentam as bordas em forma de guirlandas devido ao caráter um pouco decor. rente das nervuras secundárias; o exemplar GP/ 3T $1724 \mathrm{aA}$ expōe nervuras medianas com aspecto decorrente em apenas um lado da pina, possivelmente como resultado de uma torção do ráquis. Devido ao calibre bastante grosso das nervuras secundárias e à sua densidade relativamente grande, as áreas interneurais geralmente såo muito estreitas, em forma de vírgula. Em alguns exemplares (GP/3T 1667aA, Fig. 21, $1719 \mathrm{~A}, 1720 \mathrm{a} / \mathrm{bA}$ ), os ramos das dicotomias das nervuras secundárias aparentam estar fundidos entre si, provavelmente devido ao seu achatamento por compactaçāo dos sedimentos e calibre grosso. O exemplar GP/3T 1667aA (Fig. 21) apresenta impressōes de células alongadas preservadas nas regiōes das nervuras e de células mais arredondadas nas regioes intermediárias. As dimensões dos representantes desta espécie săo fornecidos na Tabela 1.

Discussāo - $P$. dolianitii apresenta algumas feiçōes semelhantes a Santhalea bansloiensis Maithy, 1977, como a forma geral e a disposição das pínulas, coalescência na base e, em alguns casos, a nervaçăo secundária; no entanto, distingue-se pela nervação muito mais robusta e um pouco menos densa, pela nervura mediana não decorrente, pela presença de sulco ao invés de carena no ráquis e pelo tamanho menor das pínulas. Em $S$. bansloiensis há pinulas com nenhuma ou até duas dicotomias nas nervuras secundárias, o que poderia eventualmente ser observado em frondes mais completas de $P$. dolianitit.

$\mathrm{O}$ exemplar Am.Pb. 175 de um afloramento da Formação Rio do Rasto, determinado como $P$. pedrasica Read, 1941 em CAZZULOKLEPZIG (1978), poderia corresponder a $P$. dolianitii; apesar da forma mais pronunciadamente falciforme das pinulas, com margens incompletas (e não lobadas!), sua nervação secundária parece idêntica à dos exemplares aqui estudados. Portanto, não pode ser considerado como $P$. pedrasica, cujas principais características săo: pínulas retilíneas de margens lobadas e nervuras secundárias com 3 dicotomias (READ, 1941). Outras observaçōes sobre $P$. pedrasica 
sฮ̄o apresentadas na discussăo de Pecopteris sp. 3 deste trabalho.

$\mathrm{O}$ espécime GP/3T 1716 (Figs. 3c, 23) de $P$. dolianitii, quanto à nervaçăo, assemelha-se ao exemplar da Formação Irati estudado por BORTOLUZZI (1975) e classificado como Pecopteris sp.; no entanto, é distinto em relação à presença de sulco ao invés de carena no ráquis, posição menos contígua das pinulas, angulo mais agudo de inserção das pinulas e tamanho um pouco menor.

Os exemplares analisados distinguem-se das demais pecopterídeas gonvânicas conhecjdas, mesmo considerando a sua relativa simplicidade. $P$. dolianitii é a espécie mais frequeente nos afloramentos estudados e pode estar relacionada a outras espécies descritas como $P$. bracatigaensis, $P$. esperancensis ou Pecopteris sp.3. Por outro lado, $P$. dolianitii é uma espécie bastante abrangente $e$ talvez haja a necessidade de desdobrá-la em outras, dependendo da coleta de exemplares mais completos e melhor preservados.

Pecopteris esperancensis $\mathrm{n}$. \$p. Figs. 4, 41, e 42; Tabela 1

Holótipo - GP/3T $1650 \mathrm{a} / \mathrm{bC}$; localidadetipo: AF/GP 227 - PR 90, aproximadamente km 118,8, entre Sapopema e São Jerônimo da Serra, PR.

Outros exemplares - AF/GP 168 - GP/ 3T 1733,1734 A, B, C, 1735a/b; AF/GP $197-$ GP/3T 1736a/bA; exemplares considerados como Pecopteris cf. $P$. esperancensis: AF/GP 157 - GP/3T 545bE; AF/GP 172 - GP/3T 1738b; AF/GP 178 - GP/3T 1737A.

Epiteto especifico - esperancensis referese à região de procedência do holótipo, conhecida por Esperança, entre Sapopema e São Jerônimo da Serra, PR.

Diagnose - Pinas lanceoladas, estreitas, retilíneas, com ápices muito agudos, imparipinados, pinatífidos. Ráquis geralmente estreitos e estriados. Pinulas dispostas al ternadamente, formando normalmente ângulos de $60^{\circ}$ a $75^{\circ}$ com o ráquis, contíguas e imbricadas, coalescidas lateralmente na base, apresentando forma oblonga, pouco falsiforme, com margens inteiras, lisas, subparalelas, ápice arredondado e razão comprimento por largura, na maioria dos casos, entre 1,8 e 2,2. Nervura mediana das pinulas estreita e decorrente, com terminação aparentemente em dicotomia. Nervuras secundárias caracterizadas por calibre mais ou menos fino, ocorrendo cerca de 8 a 10 em cada lado da nervura mediana, distribuidas não muito densamente conforme o padrāo catadrômico, mas opostas um pouco antes do meio ao ápice das pinulas; nervuras secundárias nitidamente decorrentes, emitidas segundo os ângulos, em média, entre $45^{\circ}$ e $65^{\circ}$, um pouco encurvadas para as margens, com uma dicotomia aproximadamente na metade da distância entre a nervura mediana e as margens; dicotomia representada por um par de ramos simétricos, côncavos entre si, alcançando as margens ainda um pouco inclinados $\left(80^{\circ}\right.$ a $\left.85^{\circ}\right)$, nervuras da porçăo mais distal das pinulas encurvadas para os ápices.

Observações adicionais - 0 ráquis da pina do exemplar GP/3T 1736 (Fig. 42) apresenta sulco e pontos irregulares de origem discutivel (cicatrizes de inserção de pelos ou marcas deixadas por pequenas concreções de óxidos de ferro). As pínulas do mesmo exemplar são alternas na regiāo proximal da pina, passando a opostas na porção distal. Os outros exemplares possivelmente têm um reforço longitudinal no ráquis. As nervuras medianas ocasionalmente estão estriadas. Os dados quantitativos são fornecidos na Tabela 1.

Discussão - $P$. esperancensis assemelhase a Pecopteris (Asterotheca?) frenguelli Archangelsky \& de la Sota, 1960 pela forma e dimensōes das pinas e pinulas, pela proximida. de das pínulas e pelo padrāo geral da nervação secundária, distinguindo-se principalmente em relaçăo aos ângulos de inserçāo das pínulas no ráquis e das nervuras secundárias na nervura mediana, à decorrência das nervuras e à nervura mediana dicotomizada no ápice das pinulas.

P. esperancensis difere de Dichotomopteris asansolioides Pant \& Misra, 1983. pelas pinulas menos próximas entre si, as quais sâo relativamente mais estreitas e menores, e pelo ponto de dicotomia das nervuras secundárias mais afastado da nervura mediana, nunca havendo uma segunda dicotomia mais distal.

$P$. esperancensis distingue-se de $P$. dolianitii principalmente pelos ápices das pinas mais agudos, pelas pinulas relativamente mais curtas, menores, mais próximas entre si, inseridas segundo ângulos um pouco mais abertos, pela nervura mediana fina e decorrente e pelo número menor de nervuras secundárias, as quais apresentam ramos dicotômicos mais abertos e simé. tricos na metade do curso, com calibre mais fino, e menor encurvamento para as margens.

O espécime de Pecopteris da Formaçāo Rio do Rasto ilustrado em MENDES (1954, 


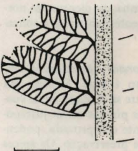

a

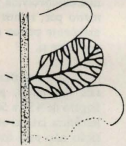

b
Figura 4 - Pecopteris esperancensis $n$. SD. escala = $3 \mathrm{~mm}$ : (a) holbtipo, afloramento AF/GP 227. exemplar GP/3T $1650 \mathrm{bC}$; (b) afloramento AF/GP 168, exemplar GP/3T $1734 \mathrm{~B}$.
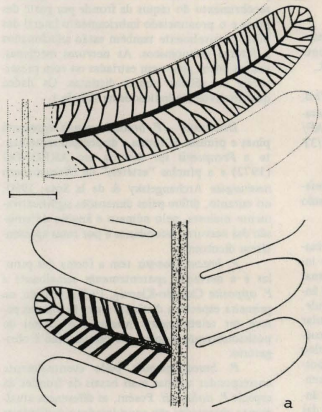

a
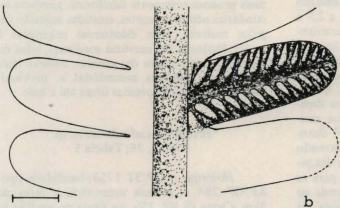

b
Figura 5 - Pacopteris bracatin geensis n. sp., afloramento AF/GP 197 exemplar GP/3T $1669 \mathrm{bB}$, escala $=3 \mathrm{~mm}$.
Figura 6 - Pecopteris cadeadensis n. sp., holótipo, afloramento AF/GP 284, exemplar GP/3T 1753, escala = $3 \mathrm{~mm}$ : (a) impressão de superficie adaxial; (b) impressáo da superficie abaxial. 
Est. 1, fig. 1) é muito semelhante ao exemplar $\mathrm{GP} / 3 \mathrm{~T} 1736 \mathrm{a} / \mathrm{bA}$ do presente estudo, devendo ser incluído em $P$. esperancensis.

$\mathrm{O}$ exemplar $\mathrm{Am} . \mathrm{Pb} .133$ ilustrado em CAZZULO-KLEPZIG (1978) e considerado como Pecopteris sp.II também deve corresponder a $P$. espenancensis, pois quase todos os seus aspectos diagnósticos estão representados. $\mathrm{Na}$ fotografia do exemplar mencionado não são visí. veis as duas dicotomias sucessivas das nervuras secundárias citadas na sua descrição.

\section{Pecopteris bracatingaensis $\mathrm{n}$. sp.} Figs. 5, 24 a 27; Tabela 1

Holótipo - GP/3T 1740a/cA; localidadetipo: AF/GP 197 - BR 373, aproximadamente km 103,8, entre Prudentópolis e Relógio, PR.

Parátipos - AF/GP 197 - GP/3T 1667bB, $1669 \mathrm{a} / \mathrm{bB}, 1739$, 1740; exemplares considerados como Pecopteris of, $P$, bracatingaensis: AF/ GP 187 - GP/3T 1741; AF/GP 210 - GP/3T $1714 \mathrm{a} / \mathrm{b} ; \mathrm{AF} / \mathrm{Gp} 194$ - GP/3T 1718A.

Epiteto especifico - bracatingaensis refere-se ao Rio Bracatinga, cujas cabeceiras estão localizadas próximo à localidade-tipo.

Diagnose - Frondes pelo menos bipinadas, com ráquis apresentando cicatrizes de inserção de pelos. Pinas em disposição alterna, lateralmente bastante imbricadas, formando àngulos de $45^{\circ}$ a $50^{\circ}$ com o ráquis da fronde. Forma das pinas aproximadamente triangular (ápices desconhecidos). Ráquis das pinas estriados longitudinalmente, com incipiente sulco mediano. Pínulas alternas ou raramente opostas, bastante próximas entre si, porém aparentemente livres até a base, inseridas segundo ângulos entre $70^{\circ}$ e $80^{\circ} \mathrm{em}$ relação aos ráquis das pinas. Forma das pínulas oblonga, falciforme, com margens inteiras e lisas, ápice arredondado e razão comprimento por largura igual a 2,9 a 4,1 . Nervuras medianas das pinulas caracteristicamente nåo decorrentes, bastante afiladas para o ápice, terminando em duas nervuras simétricas, cada uma, por sua vez, com uma dicotomia. Nervuras secundárias bastante robustas, estreitas, muito próximas entre si, em número superior a 15 em cada lado da nervura mediana, emitidas segundo ângulos entre $60^{\circ}$ e $70^{\circ}$ distribuídas do modo catadrômico, porém ocorrendo opostas um pouco além da porção média das pinulas; nervuras ligeiramente encurvadas para as margens, apresentando uma dicotomia mais ou menos na metade do seu curso $e$, às vezes, na porçāo média das pínulas, uma segunda dicoto- mia desenvolvida na nervura acroscópica do primeiro par; ramos de ambas as dicotomias normalmente pouco divergentes, paralelos e côncavos entre si.

Observaçōes adicionais - As margens laterais das pinas, próximo à base, formam um ângulo de $45^{\circ}$ a $50^{\circ}$ entre si. A ausência de coalescência lateral entre as pínulas ou de justaposição nāo está totalmente comprovada, podendo ser um problema de preservação. Os ápices das pínulas, às vezes, ocorrem imbricados, mas provavelmente não durante a vida do vegetal. $O$ recobrimento do ráquis da fronde por parte das pinas e o pronunciado imbricamento lateral das pinas possivelmente também estão relacionados a fatores tafonômicos. As nervuras medianas, vez ou outra, aparecem estriadas ou com preservação de células pouco distintas. Os dados quantitativos sáo indicados na Tabela 1.

Discussāo - $P$. bracatingaensis apresenta pinas e pínulas de forma e disposiçāo semelhante a Pecopteris sp. descrita em ARRONDO (1972) e a pinulas "estéreis" de Dizeugotheca neuburgiae Archangelsky \& de la Sota, 1960; no entanto, difere pelas dimensóes significativamente maiores, pelo número e ângulo de emissđ̃o das nervuras secundárias e por estas apresentarem dicotomias.

$P$. bracatingaensis tem a forma das pinulas e a nervação aparentemente semelhante a P. opposita Cazzulo-Klepzig, 1978; contudo, na primeira espécie, a distância entre as pínulas pa. rece ser relativamente menor e o caráter de posicionamento oposto das pinulas năo é obri. gatório.

P. bracatingaensis pode eventualmente corresponder a pinas mais basais de frondes da espécie $P$. dolianitii. Porém, as diferenças atualmente observadas saio consideradas significativas e suficientes para discemir as espécies: forma mais proeminentemente falciforme, nervuras secundárias não decorrentes, emitidas segundo ângulos maiores, com dicotomias originadas à maior distância das nervuras medianas, além do tamanho médio maior das pinulas, número mais elevado de nervuras secundárias e, provavel. mente, margens das pínulas livres até a base.

\section{Pecopteris cadeadensis n. sp.} Figs. 6, 38; Tabela 1

Holótipo - GP/3T 1753; localidade-tipo: AF/GP 284 - estrada secundária a cerca de $3 \mathrm{~km}$ a leste da BR 376 , na altura do $\mathrm{km} 284,6$, PR. 
Exemplar considerado como Pecopteris cf. P. cadeadensis - AF/GP 200 - GP/3T 1752.

Epiteto especifico - cadeadensis refere-se à Serra do Cadeado, onde foi coletado o holótipo da espécie.

Diagnose - Frondes pelo menos bipinadas, com ráquis robustos, exibindo cicatrizes mais ou menos triangulares de inserção de pelos. Pinas aparentemente alternas e inseridas segundo ângulos provavelmente quase retos, apresentando forma oblonga de grande comprimento (ápice das pinas desconhecido, supostamente mais ou menos agudo e imparipinado). Ráquis das pinas proeminente, expondo cicatrizes de inserção de pelos na provável superfície abaxial e uma carena na adaxial. Pinulas inseridas aos ráquis segundo àngulos entre $70^{\circ} \mathrm{e} 75^{\circ}$. geralmente ocorrendo opostas ou também alternas, próximas entre si e com as margens laterais justapostas ou coalescidas na regiāo basal. Forma das pinulas oblonga, praticamente simétrica e retilinea, com ápice arredondado, margens laterais inteiras e lisas, base totalmente atada ao ráquis, apresentando razđo de comprimento por largura, em média, igual a 2,5. Nervura mediana das pínulas sempre arrematada com uma dicotomia, caracterizando-se, na suposta superfície abaxial, por acentuada robustez, base um pouco decorrente, relativamente larga, ápice muito adelgaçado, com pequenas cicatrizes de inserção de pelos, e na provável superfície adaxial, aparecendo mais estreita, em suave ziguezague, com possível carena. Nervuras secundárias, sempre em número igual a $10-12$ em cada lado da nervura mediana, emitidas segundo ân. gulos entre $35^{\circ}$ e $55^{\circ}$, pouco decorrentes, quase retilíneas, ligeiramente encurvadas para as margens, relativamente afastadas entre si, com padrão de distribuição marcadamente catadrô. mico, aparecendo opostas somente na região apical das pínulas. Dicotomias nas nervuras secundárias originadas à pequena distância da nervura mediana, resolvendo-se em ramos muito próximos entre si e quase paralelos, porém, na região apical das pínulas, dicotomias posicionadas mais afastadas da nervura mediana e caracterizadas por ramos mais divergentes e concavos entre si.

Observaçōes adicionais - $\mathrm{O}$ holótipo tem pinas bem preservadas, entretanto, há dobras ou rupturas nas regiōes de inserção dos seus ráquis aos ráquis das frondes. A impressão da superfície supostamente abaxial (Fig. 38c) das pinulas ocorre um pouco convexa; suas áreas interneurais aparecem como proeminéncias estreitas, mais ou menos gutiformes alongadas, formando, em conjunto, um padrão de aspecto pinado. A provável superfície adaxial (Fig. 38a) ocorre quase plana a côncava nas impressōes, sem grandes contrastes de relevo entre as áreas interneurais e as nervuras (também preservadas em depressão); a forma em zigue-zague das nervuras medianas é condicionada pelos pontos de emis. săo das nervuras secundárias. Nas impressōes de ambas as superfícies, na base e na porção média das pinulas, as nervuras secundárias muitas ve. zes têm os ramos dicotômicos virtualmente não individualizados, provavelmente devido ao seu achatamento durante a compactação, sendo perceptíveis, na maioria dos casos, em virtude do aumento da largura das depressōes correspondentes às impressóes das nervuras ao longo do seu curso. Na impressáo da suposta superfície abaxial, estas depressōes aparecem retilíneas a ligeiramente convexas com relação à nervura mediana, porém côncavas na superfície adaxial. As dimensōes são fornecidas na Tabela 1.

Discussāo - A interpretação a respeito das superficies abaxiais $e$ adaxiais das pinulas baseia-se na coincidência dos valores numéricos e das principais características mor fológicas nos exemplares nas duas situaçōes, encontrados no mesmo nível da amostra. A identificaçāo de uma ou de outra superfície está fundamentada no fato de a nervaçáo e os ráquis geralmente sobressaírem mais na face abaxial e a superfície convexa das pinulas normalmente representar a porção adaxial. O problema do padrão de encurvamento aparentemente distinto das nervuras secundárias de uma para a outra face deve ser ilusório. Este aspecto reflete, possivelmente. algumas diferenças na eficiência do decalque ou no próprio calibre dos ramos dicotômicos acros. cópicos em relação aos basiscópicos, variando conforme a face do limbo. Pode haver influência de deformaçōes e exagero na reprodução de certas feiçōes do limbo original devido a fatores tafonômicos.

Pecopteris sp. em CAZZULO-KLEPZIG \& CORREIA (1981) tem pinulas de forma e tamanho semelhante a $P$. cadeadensis, possivelmente correspondendo à mesma espécie. Suas nervuras secundárias aparecem melhor preserva. das, com uma dicotomia mais evidente. Se a identidade das formas for confirmada, o ápice das pinas de $P$. cadeadensis (não preservado no holótipo) seria comprovadamente imparipinado e mais ou menos agudo.

$P$. cadeadensis distingue-se de $P$. dolianitii por apresentar pinas de forma oblonga, pinulas 
mais retilíneas e de margens menos paralelas. decorréncia mais pronunciada das nervuras medianas, presença de carenas ao invés de sulcos nos ráquis das pinas, traçado mais retilíneo das nervuras secundárias e ramos dicotômicos das nervuras menos divergentes.

Os exemplares GP/3T $1667 \mathrm{aA}, 1720 \mathrm{a} / \mathrm{bA}$ e principalmente GP/3T 1719A, considerados como $P$. dolianitii, assemelham-se a $P$. cadeadensis pelos ramos das dicotomias virtualmente ñ̃o separados, porém se diferenciam pela forma das pinas mais lanceolada e pela forma das pinulas mais oblonga $e$ falciforme.

Pecopteris sp. 1

Fig. 7. 28 e 29; Tabela 1

Exemplares e procedência - AF/GP 185 - GP/3T 1754a/bA; AF/GP 178 - GP/3T 1742A, 1743aA AF/GP $194-$ GP/3T 1744A; AF/GP 275 - GP/1T $1391 \mathrm{c} / \mathrm{dF}$.

Descriçāo - Pecopteris sp.1 corresponde a fragmentos de pinas, possivelmente nåo todos pertencentes à mesma espécie (de forma lanceolada no exemplar GP/1T 1391 c/dF, Fig. 29). O ráquis aparentemente tem estrias. As pinulas inserem-se com toda a sua porção basal ao ráquis, segundo ângulos entre $55^{\circ}$ e $75^{\circ}$; ocorrem alnernas nos exemplares GP/1T 1391 c/dF e GP/ 3T $1743 \mathrm{aA}$ e aparecem relativamente afastadas umas das outras (distância entre as pínulas igual a cerca de $1 / 3$ de sua largura). As pínulas sāo oblongas, quase retilíneas, levemente encurvadas para a porção distal, com margens inteiras, lisas e ápice arredondado. As nervuras medianas são estreitas, possivelmente decorrentes e terminadas em dicotomia no exemplar GP/3T 1754a/ bA (Fig. 28). As nervuras secundárias dispōem. se relativamente afastadas entre si, em número de 10 a $12 \mathrm{em}$ cada lado da pinula, opostas a subopostas, e são emitidas aos ângulos entre $50^{\circ}$ e $60^{\circ}$ Caracterizam-se por uma dicotomia originada praticamente junto à nervura mediana. formada por ramos muito pouco divergentes e quase paralelos, às vezes. aparecendo nos fósseis como uma única estrutura alargada e um pouco encurvada em direção às margens laterais das pinulas. As áreas interneurais apresentam forma mais ou menos retangular ou trapezoidal, sem diferença de relevo acentuada em relação às nervuras. Particularmente no exemplar GP/3T $1754 \mathrm{a} / \mathrm{bA}$ (Fig. 28) há um aparente e sutil imbricamento destas áreas, da base para o ápice das pinulas. Os dados quantitativos de Pecopteris sp. 1 são indicados na Tabela 1.

Discussāo - Entre as espécies de pecopte- rideas conhecidas do Gondvana, nenhuma apresenta caracteristicas suficientemente semelhantes a Pecopteris sp. 1 que valha ser citada. Pecopteris sp. 1 difere de $P$. dolianitii pelo maior afastamento entre as pinulas, pela nervação de calibre mais fino, pelos ramos dicotômicos das nervuras menos divergentes e pelas áreas interneurais mais largas, nð̄o em forma de vírgula. Distingue-se de $P$ cadeadensis quanto à forma das pínulas e seu distanciamento, à nervura mediana mais estreita $e$ às áreas interneurais um pouco mais largas. Exemplares melhor preservados, provavelmente. permitirão erigir outra espécie nova.

Pecopteris sp. 2

Figs. 8. 39 e 40; Tabela 1

Exemplares e procedência - AF/GP 157 - GP/3T 547A. 551; AF/GP 178 - GP/3T 1747A, 1748B. C. exemplar considerado como Pecopteris of. $P$. sp.2: AF/GP $194 \quad$ GP/3T $1749 \mathrm{a} / \mathrm{bA}$.

Descriçâo Pecopteris sp. 2 abrange frag. mentos de pinas de margens paralelas (e uma pinula isolada: GP/3T 547A), com ráquis aparentemente estriados. As pinulas ocorrem em posi. ção alterna, inseridas segundo ângulos entre $55^{\circ}$ e $82^{\circ}$, apresentando forma levemente fal. ciforme, oblonga, proximalmente mais larga. com margens laterais nitidamente coalescidas na região basal, inteiras e lisas na porção média, e ápice estreito e arredondado; as margens no lado basiscópico das pinulas apresentam curvatura suave, praticamente constante da base ao ápice; porém, no lado acroscópico, são mais en. curvadas, principalmente na porção proximal da pinula, encontrando-se perpendiculares ou obtusas em relação ao ráquis. No exemplar GP/ 3T 1747A (Fig. 40), as impressōes das pinulas ocorrem relativamente convexas. As nervuras medianas aparecem mais ou menos estreitas ou obtusas, pouco ou náo decorrentes, com terminação aparentemente em dicotomia. As nervuras secundárias ocorrem mal preservadas, em número de 12 a 15 em cada lado da pinula: apresentam calibre mais ou menos fino; distribuem-se conforme o padrão catadrômico, porém aparecem opostas a partir da porção média das pínulas; são emitidas segundo ângulos entre $50^{\circ}$ e $55^{\circ}$ (ou até $73^{\circ}$ no exemplar GP/3T 547A). No exemplar GP/3T 1747A (Fig. 40). as nervuras secundárias são caracterizadas por uma dicotomia bastante próxima à nervura mediana, com ramos dicotômicos relativamente divergentes e freqüentemente côncavos entre si. 


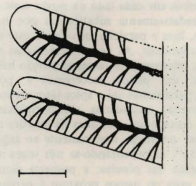

Figura 7 - Pecopteris sp. 1, afloramento AF/GP 185 , exemplar GP/3T $1754 \mathrm{bA}$, escala $=3 \mathrm{~mm}$.

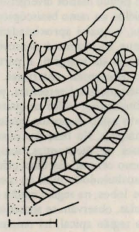

Figura 8 - Pecopteris $\mathrm{sp} .2$, afloramento $\mathrm{AF} /$ GP 178, exemplar GP/3T $1747 \mathrm{~A}$, escala $=3 \mathrm{~mm}$.

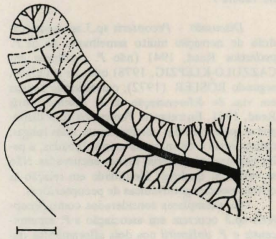

Figura 9 - Pecopteris sp. 3 , afloramento AF/ GP 168, exemplar GP/3T 1745aA, escala = $3 \mathrm{~mm}$.

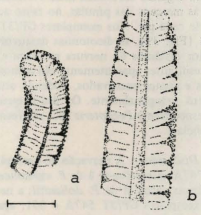

Figura 10 - PDizeugotheca sp. escala $=3 \mathrm{~mm}$ : (a) afloramento $A F / G P$ 157, exempiar GP/3T 546aB; (b) afloramento AF/GP 197, exemplar GP/3T $1667 \mathrm{C}$.

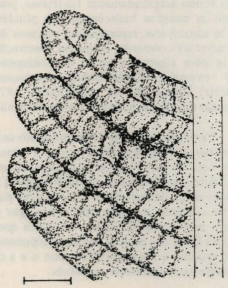

Figura 11 - ?Dizeugotheca bortoluzzii Cazzulo-Klepzig, afloramento AF/GP 157. exemplar GP/3T 1751aA, escala = $3 \mathrm{~mm}$. 
encurvados para as margens; esporadicamente há uma segunda dicotomia mais ou menos pró. xima às margens das pinulas, no ramo acroscópico de cada par. Nos exemplares GP/3T 547A e 551 (Fig. 39), as dicotomias desenvolvem-se à maior distância da nervura mediana e os ramos resultantes aparentemente são menos divergentes e menos encurvados, podendo atingir as margens ortogonalmente. Os dados quantitativos respectivos a Pecopteris sp. 2 sāo fornecidos na Tabela 1.

Discussão - A nervação do exemplar GP/ 3T 1747 A assemelha-se à de $P$. esperancensis e, em alguns casos, à de $P$. dolianitii; a nervação dos exemplares GP/3T $547 \mathrm{~A}$ e 551 , aparentemente, é similar ao padrāo apresentado pelo exemplar GP/3T $546 \mathrm{aC}$, considerado como $P$. dolianitii. A principal feição que distingue $P e$ copteris sp. 2 das espécies mencionadas é a forma das pinulas e sua evidente uniāo lateral nas bases. Pecopteris sp.2, à primeira vista, é semethante ao gênero Alethopteris (WAGNER, 1968) devido à coalescência basal das pínulas e sua forma acentuadamente falciforme, porém possui as margens basiscópicas das pínulas, e ño as acrocópicas, representadas por uma linha de curvatura constante. A mesma observação é válida para algumas espécies de Cladophlebis (por exemplo, Cladophlebis mendozaensis (Geinitz) Frenguelli, em ARRONDO, 1972), além das diferenças quanto à forma das pínulas, etc.

Exemplares melhor preservados sáo necessários para caracterizar Pecopteris sp. 2 como espécie nova ou para verificar se a forma não seria resultante, por exemplo, de ressecamento das frondes antes da deposiçăo. Tal processo poderia ter enrolado ou envergado as margens dos limbos para a porção abaxial de modo que as porçб̄es livres das pinulas ficassem virtualmente mais estreitas e mais afastadas entre si e a coalescência basal aparecesse ressaltada.

\section{Pecopteris sp. 3}

Figs. 9, 35 a 37; Tabela 1

Exemplares e procedéncia - AF/GP 168 - GP/3T 1745a/cA, aB, a/dD, bE; AF/GP 197 - GP/3T 1746A.

Descriçāo - Em Pecopteris sp. 3, as pinas ocorrem muito fragmentadas. O ráquis é finamente estriado. As pínulas estão inseridas ao ráquis ao ângulo de $60^{\circ}$ a $80^{\circ}$, em posição alterna a oposta, muito próximas entre si e coalescidas lateralmente na região basal. As pínulas săo pouco a acentuadamente falciformes; exibem 2 ou 3 lobos em cada lado na regiāo mais proximal, gradativamente substituidas por margens inteiras, lisas e paralelas até o ápice, este de forma arredondada. As nervuras medianas são estriadas, relativamente largas na porção basal das pínulas, um pouco decorrentes e, possivelmente, persistentes até o ápice (sem dicotomia). As nervuras secundárias sāo complexas, um pouco decorrentes, emitidas da nervura mediana quase retilíneas, normalmente ao ângulo de $45^{\circ}$ a $55^{\circ}$, dicotomizando-se três vezes na porção média das pínulas; a primeira dicotomia ocorre mais ou menos próximo à nervura mediana, originando pares de ramos bastante divergentes; a segunda dicotomia é gerada do ramo acroscópico da primeira, ainda à pequena distảncia da nervura mediana, derivando pares de nervuras um pouco menos divergentes e mais ou menos paralelos ao ramo basiscópico da primeira dicotomia, o qual é aproximadamente retili. neo; a terceira dicotomia é desenvolvida à pe. quena distância da margem, a partir do ramo central das dicotomias anteriores, originando nervuras ainda menos divergentes, porém ainda bem individualizadas; todos os quatro ramos de cada conjunto estão dispostos quase ortogonalmente às margens. $\mathrm{Na}$ base das pínulas, há um número maior de dicotomias, sempre progredindo do ramo central das duas primeiras dicotomias e distribuindo-se mais ou menos simetricamente nos lobos; na regiāo média a quase apical das pinulas, observam-se somente duas dicotomias e na regiáo apical, há remanescência de apenas uma. As nervuras secundárias estão moderadamente concentradas, emergindo de cada lado da nervura mediana um número igual a 15 até aproximadamente 19 nervuras, com padrão de distribuição catadrômico somente evidente na regiāo basal. As dimensōes são fornecidas na Tabela 1.

Discussão - Pecopteris sp. 3 apresenta pa. drão de nervaçāo muito semelhante ao de $P$. pedrasica Read, 1941 (náo $P$. pedrasica em CAZZULO-KLEPZIG, 1978) que, na realidade, segundo RÖSLER (1972), corresponde a pinas em vias de diferenciação de $P$. cambuhyensis Read, 1941. Entretanto, Pecopteris sp. 3 distingue-se pelas pinulas relativamente mais longas, menos retas e de margens menos lobadas, e pelas nervuras secundárias menos encurvadas. Não se verificou qualquer identidade em relação às outras espécies gondvânicas de pecopterídeas.

Os exemplares considerados como Pecopteris sp. 3 ocorrem em associaçáo a $P$. espenancensis e $P$. dolianitii nos dois afloramentos onde foram coletados. $P$. esperancensis, igualmente com nervuras decorrentes, pínulas contiguas 
e coalescidas na base, poderia corresponder a pinas jâ completamente diferenciadas de frondes portanto pinas do tipo Pecopteris sp. 3 em vias de diferenciaçăo. Quanto a $P$. dolianitii, esta hipótese é mais remota pelas aparentes diferenças quanto aos ângulos de inserção das pínulas e das nervuras, à contiguidade das pínulas e à divergência dos ramos dicotômicos das nervuras. O exemplar GP/3T $1669 \mathrm{a} / \mathrm{bB}$, considerado como $P$. bracatingaensis, assemelha-se bastante a Pecopteris sp.3, e em especial ao exemplar GP/ 3T 1746A, do mesmo afloramento, sugerindo uma relação também entre estas espécies.

\author{
Divisāo FILICOPHYTA \\ Classe EUSPORANGIOPSIDA \\ Ordem MARATTIALES \\ Familia ASTEROTHECACEAE \\ Gênero ?Dizeugotheca Archangelsky \& de la \\ Sota, 1960 \\ ?Dizeugotheca sp. \\ Figs. 10,31 a 34 \\ Exemplares e procedência - AF/GP 157 \\ - GP/3T 545aC, 546a/bB, 548bF, 550aA, \\ $1750 \mathrm{bA} ; \mathrm{AF} / \mathrm{GP} 197$ - GP/3T $1667 \mathrm{C}$.
}

Descriçāo - 2Dizeugotheca sp. é representado por fragmentos de pinas e pinulas isoladas, mal preservadas, provavelmente férteis. $O$ exemplar GP/3T 550aA (Fig. 33) corresponde à porção mais ou menos apical de uma pina, sem ráquis bem preservado, tendo pinulas alternas, contíguas, inseridas segundo ângulos entre $58^{\circ}$ e $68^{\circ}$. Estas pinulas, além daquelas dos exemplares GP/3T $545 \mathrm{aC}$ e $1750 \mathrm{bA}$ (Fig. 32), apresentam forma oblonga, com margens laterais dobradas para a face abaxial e geralmente quebradas, ápice arredondado, às vezes, um pouco encurvado para o lado distal (bases normalmente muito mal preservadas). As nervuras medianas estão obscuras e aparecem como delgadas linhas mais ou menos sinuosas, aparentemente dicotomizadas uma vez no final, limitando cerca de 9 possíveis sinângios em cada lado da pínula; os supostos sinângios têm forma retangular a pentagonal alongada, geralmente arredondada na porção próxima às margens das pinulas; aparecem contíguos, quase perpendiculares à "nervura" mediana das pínulas, opostos a subopostos; há uma pequena inflexăo longitudinal nestas estruturas, mais pronunciada próximo às margens das pinulas, possivelmente correspondendo ao limite entre dois esporângios. O exemplar GP/3T 1667C (Fig. 34) ế representado por pínula mais ou menos retilínea, incompleta nas duas extremidades, ligeiramen- te cuneiforme, tendo dimensōes maiores do que as apresentadas na Tabela 1 para os outros exemplares (largura $=4,6 \mathrm{~mm}$, comprimento superior a $14,1 \mathrm{~mm})$; ostenta uma nervura mediana larga e robusta, e um número superior a 14 prováveis sinângios em cada lado, grosseiramente elípticos, com largura máxima aproximadamente igual a $1 \mathrm{~mm}$, que ocorrem contíguos, opostos e mais ou menos transversais à nervura mediana; estas estruturas também apresentam uma linha divisória longitudinal, provavelmente correspondendo ao limite entre dois esporân. gios.

Discussāo - A má preservação dos exemplares considerados como ?Dizeugotheca sp. nāo permite avançar além das especulaçōes apresentadas. De qualquer forma, as pinulas ñ̃o exibem um padrão normal de nervação $e$ sim, corpos capsulares que coadunam, por exemplo, com os sinângios em Dizeugotheca branisae Arrondo, 1967, porém, diferindo quanto à forma e ao número.

\section{?Dizeugotheca bortoluzzii Cazzulo-Klepzig. 1978}

Figs. 11, 30; Tabela 1

Exemplares e procedència - AF/GP 157 - GP/3T 548bD, 550aC, $1751 \mathrm{a} / \mathrm{bA}$.

Descrição - Os exemplares considerados como ?Dizeugotheca bortoluzzii correspondem a fragmentos de pinas e pinulas isoladas de filicineas provavelmente férteis. As pinas são oblongas, sem base, ápice e ráquis preservados. tendo pínulas inseridas segundo ângulos entre $70^{\circ}$ e $75^{\circ}$, aparentemente alternas e contiguas. As pinulas são falciformes, oblongas, com ápices arredondados, margens laterais aproximadamente lisas, inteiras, dobradas um pouco para a face abaxial e, na maior parte dos casos, incompletas. As pínulas siio caracterizadas por estreita "nervura" mediana, pouco regular, e por bandas estreitas, decorrentes desta "nervura", suavemente encurvadas, que alcançam as margens mais ou menos ortogonalmente. Estima-se um número igual a 12 bandas em cada lado da pínula; sฮ̄o mal limitadas e aparecem irregularmente, em relevo ou em depressão, às vezes imbricadas, provavelmente correspondendo a esporângios ou a sinângios.

Discussão - Os exemplares aqui designados como 2 . bortoluzzii distinguem-se das formas determinadas como Pecopteris pela ausência de nervuras secundárias visíveis e pela ocorrência de bandas atribuiveis, embora de 
maneira discutível, a estruturas de reprodução. Lembram os sinângios em $D$. neuburgiae Archangèlsky \& de la Sota, 1960, porém, faltam dados para uma comparação mais efetiva. Os fósseis aqui estudados provavelmente são similares aos exemplares descritos como $D$. bortoluzzii em CAZZULO-KLEPZIG (1978). No entanto, alguns daqueles espécimes apresentam sinângios melhor individualizados e não imbricados, embora pareçam quase tão precariamente preservados quanto os do presente trabalho. Apesar de concordar com CAZZULO. KLEPZIG (1978) em relação à distinção da espécie das demais formas gondvânicas, faltam dados mais precisos para a sua caracterização.

\section{AGRADECIMENTOS}

Silvia Czajkowski e Eleuze Mendonça tiveram importante participação nos trabalhos de campo; Claudio Riccomini gentilmente forneceu o holótipo de Pecopteris cadeadensis e as informaçōes necessárias sobre a localidadetipo; Thomas R. Fairchild corrigiu o "abstract"; Alfredo G. Rohn colaborou nos serviços de fotografia. A estas pessoas, os autores expressam seus sinceros agradecimentos.

\section{REFERENCIAS BIBLIOGRÄFICAS}

ARCHANGELSKY, S, \& DE LA SOTA, E. (1960) Contribución al conocimiento de las filices permicas de Patagonia Extraandina. Act. Geol. Lilloana, 3: 85-126.

ARRONDO, O.G. (1967) "Dizeugotheca branisae" n.sp. nueva filice eusporangiada del Permico Inferior, Bolívia, Rev. Mus. La Plata (N. Ser.), 5 (Paleontol.): 55-61.

ARRONDO, O.G. (1972) Estudio geologico y paleontologico en la zona de la Estancia La Juanita y alredores, Provincia de Santa Cruz, Argentina. Rev, Mus. La Plata (N. Ser.), 7 (Paleontol. 43): 1-194.

BORTOLUZZI, C.A. (1975) Étude de quelques empreintes de la flore gondwaniénne du Brésil. $95^{\text {éme }}$ Congr. Natl. Soc. Savantes, Reims, Bibliothèque Nationale, Comptes Rendus, p. 171-187.

CAZZULO-KLEPZIG, M. (1978) Estudo da tafoflórula do Membro Morro Pelado na sua localidade-tipo. Pesquisas, $11: 225-303$.

CAZZULO-KLEPZIG, M. \& CORREIA, N. dos R. (1981) Contribuiçāo ao estudo da tafoflora permiana no Membro Serrinha na Serra do Cadeado, Estado do Paraná , Brasil. II Congr. Latino-Am. Paloontol., Porto Alegre, Anais, $1: 233-247$

DOLIANITI, E. (1945) Um novo elemento na flora fóssil do Brasil, "Sphenozamites" Brongniart. DGM, DNPM, Not. Prelim. e Est., 26: 1-4.

MAITHY,P.K. (1977) Three new fern fronds from the Glossopteris Flora of India. Palaeobot., 24(2):96-101.

MENDES, J.C. (1954) Contribuiçāo à estratigrafia da Série Passa Dois no Estado do Paraná. Bol. Fac. Fil. Ciênc. Letr., Univ, Sāo Paulo, 175 (Geol., 10), 119p.

OLIVEIRA, E.P. (1918) Anexo. In: HOLDHAUS, K. Sobre alguns lamelibrânquios fósseis do sul do Brasil. SGM, Monogr., 2: 27-32.

PANT, D.D. \& MISRA, L.A. (1983) Cuticulatopteris gen. Nov. and some other pteridophylls from The Raniganj Coalfield, India (Lower Gondwana). Palaeontogr. Abt. B, 185 (1-3): 27-37.

READ, C.B. (1941) Plantas fósseis do Neo-Paleozóico do Paraná e Santa Catarina, DGM, DNPM, Monogr., 12, 102p.

RIGBY, J.F. (1968) New fossil locality near Laras, State of São Paulo. XXII Congr-brasil. Geol., Belo Horizonte, Anais, p. 201-208.

RÖSLER, O. (1972) Flora da Formação Rio Bonito no Estado do Paraná. Tese de doutoramento. Inst. Geociências/ USP, Săo Paulo, 130p.

RÖSLER, O. (1978) Novas ocorrência na Formaçāo Rio do Rasto, Permiano Superior, Estado do Paraná. Bol. IGUSP, 9:127-132.

WAGNER, R.H. (1968) Upper Westphalian and Stephamian species of Alethopteris from Europa, Asia Minor and North America. Mededelingen van de Rijks Geologische Dienst, Ser. C, III, 1(6), 188p. 